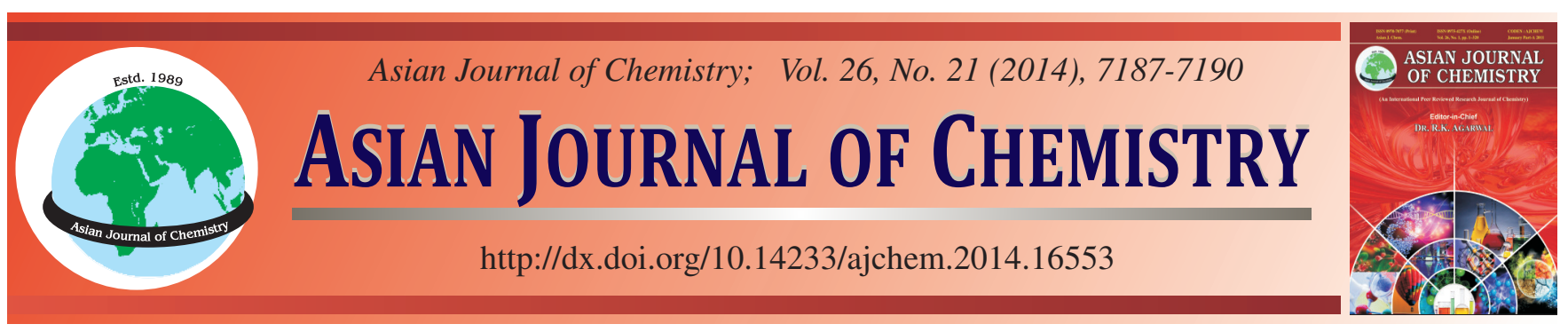

\title{
Low Temperature Hydroxylation of Benzene to Phenol on Fe/Activated Carbon Catalysts Loaded with Different Types of Second Metal Under Microwave Condition
}

\author{
T. $\mathrm{LiU}^{1, *}$ and J.H. Hou ${ }^{2}$
}

${ }^{1}$ School of Chemistry and Chemical Engineering, Xuzhou Institute of Technology, Xuzhou 221111, Jiangsu Province, P.R. China

${ }^{2}$ School of Food (Biology) Engineering, Xuzhou Institute of Technology, Xuzhou 221111, Jiangsu Province, P.R. China

*Corresponding author: E-mail: liutongcumt@126.com

\begin{abstract}
This paper investigated the microwave assisted liquid phase hydroxylation of benzene to phenol with hydrogen peroxide over Fe/activated carbon-based catalysts prepared by impregnated method. Various types of second metal (e.g., Co and $\mathrm{Cu})$ were loaded together with Fe on the activated carbon support and the catalytic performance of the obtained catalysts was compared. It was found that the presence of the second metal can improve the phenol production of the typical Fe/activated carbon catalyst. Various techniques (XRD and BET surface area) were employed to characterize the catalysts. Finally the effects of some operating variables (e.g., reaction time, catalyst amount, $\mathrm{H}_{2} \mathrm{O}_{2}$ amount, solvent amount) on the catalytic performance were investigated.
\end{abstract}

Keywords: Microwave, Hydroxylation, Benzene, Phenol, Hydrogen peroxide.

\section{INTRODUCTION}

Phenol is a valuable organic intermediates in chemical industries related to resin, pharmaceuticals, agrochemicals, nylon and other synthetic fibers ${ }^{1-3}$. Nowadays, $90 \%$ of the worldwide production of phenol is based on the cumene process, which constitutes a three-step reaction that has as main advantage the conversion of the two relatively inexpensive starting materials, benzene and propene, into the valuable chemicals phenol. However, the process suffers from many disadvantages such as the lower conversion and formation of acetone as inevitable side product ${ }^{4-7}$. Therefore, the one-step process for direct hydroxylation of benzene to phenol has attracted worldwide attention and is one of the most challenging issues in catalysis research at present ${ }^{8,9}$.

The synthesis of phenol from the direct hydroxylation of benzene can be achieved by various oxidants, including nitrous oxide $^{10}$, hydrogen peroxide ${ }^{11}$ and molecular oxygen ${ }^{12}$. Hydrogen peroxide has been widely used as a green oxidant, because it is readily available and the resulting by-products (water and molecular oxygen) are environmentally friendly ${ }^{13,14}$.

Microwave irradiation is well documented to significantly accelerate a wide range of organic reactions, especially in a polar system, under mild conditions ${ }^{15}$. Microwave irradiation heating has the following advantages compared to conventional heating for organic reactions: no direct contact between the energy source and the reacting chemicals ${ }^{16}$, reducing heat transfer problems ${ }^{17}$, energy efficiency ${ }^{18}$, easy automation and incident power control ${ }^{19}$. In numerous organic reactions, rapid heating, selective heating and enhancements of yield and purity are possible by microwave irradiation ${ }^{20}$.

In this study, we attempted to improve the catalytic properties of the Fe/activated carbon catalyst by adding second metal oxides ( $\mathrm{Cu}$ and $\mathrm{Co})$ at different compositions to the catalysts for the liquid phase hydroxylation of benzene to phenol with hydrogen peroxide at room temperature. In addition, various techniques were employed to characterize the synthesized catalysts. Finally, the effects of some operating variables such as reaction time, catalyst amount, $\mathrm{H}_{2} \mathrm{O}_{2}$ amount, solvent amount on the phenol yield were investigated.

\section{EXPERIMENTAL}

Catalyst preparation: All solvents and reagents were purchased from commercial sources and used without further purification. Activated carbon was treated by refluxing with 5 $\mathrm{M}$ nitric acid for $3 \mathrm{~h}$, then the material was washed until neutral $\mathrm{pH}$ was attained. By filtrating, the solid obtained was further dried at $70{ }^{\circ} \mathrm{C}$ overnight in vacuum. These activated carbons were then impregnated with a mixed solution of metal precursors at room temperature. For example, 5 wt. \% Fe and 2.5 wt. \% $\mathrm{Cu}$ loaded on activated carbon (abbreviated as $\mathrm{Fe}_{5} \mathrm{Cu}_{2.5} /$ C) were prepared by mixing $10 \mathrm{~g}$ of activated carbon, $0.645 \mathrm{~g}$ of Fe (e.g., $3.11 \mathrm{~g}$ of iron (III) chloride) and $0.21 \mathrm{~g}$ of $\mathrm{Cu}(e . g$., 
$0.77 \mathrm{~g}$ of cupric(II) nitrate). Then, excess solvent was done by the vacuum evaporation. The catalyst samples were further dried at $70{ }^{\circ} \mathrm{C}$ overnight in vacuum oven.

Benzene hydroxylation: Benzene hydroxylation reaction was carried out in a CEM discover microwave reactor. The reactor contents were thoroughly mixed with the help of a magnetic stirrer. Acetonitrile was used as solvent and $\mathrm{H}_{2} \mathrm{O}_{2}$ (30 wt. \%) as an oxidant. In all the experimental runs, $15 \mathrm{~mL}$ acetonitrile and $1 \mathrm{~mL}$ benzene were used. The reactor was heated to $35^{\circ} \mathrm{C}$ for 5 to $20 \mathrm{~min}$. Then the reactor was immediately cooled to room temperature by purging compressed air. The products were analyzed by gas chromatography.

Characterization: X-ray diffraction (XRD) measurements were carried out with a D/max-RA X-ray diffractometer (Rigaku, Japan), $\mathrm{CuK}_{\alpha}$ radiation at a scan rate of $3 \% \mathrm{~min}$. The tube voltage and current were $35 \mathrm{kV}$ and $35 \mathrm{~mA}$, respectively. The phases were identified by comparing the diffraction patterns to standard powder XRD cards compiled by the Joint Committee on Powder Diffraction Standards (JCPDS).

The BET surface area, total pore volume and pore size distribution of the fresh catalysts were determined via $\mathrm{N}_{2}$ physisorption at the normal boiling point of $\mathrm{N}_{2}\left(-196^{\circ} \mathrm{C}\right)$, using an Autosorb-1 MP instrument (Quanta chrome, USA).

The terms of reaction performance were defined as follows:

$$
\begin{gathered}
\text { Yield of phenol }=\frac{\text { mole of phenol produced }}{\text { Initial mole of benzene }} \\
\text { Selectivity of phenol }=\frac{\text { mole of phenol produced }}{\text { mole of benzene reacted }}
\end{gathered}
$$

\section{RESULTS AND DISCUSSION}

Evaluation of performances of various catalysts: The formulae of catalysts with different percent metal loadings are abbreviated by using subscripts; for example, $\mathrm{Fe}_{5} \mathrm{Cu}_{5} /$ activated carbon represents a catalyst with 5 wt. \% Fe and 5 wt. $\% \mathrm{Cu}$ loaded on activated carbon.

The XRD patterns of the catalysts and the blank activated carbon support were determined. However, no obvious peaks of $\mathrm{Fe}, \mathrm{Cu}$ and $\mathrm{Co}$ metals were observed when compared with the pattern of the blank activated carbon, which could be due to the low metal loading or to the oxide being in the amorphous state (not shown).

The catalytic activities of several activated carbon support second transition metal oxide catalysts in the direct hydroxylation of benzene to phenol with hydrogen peroxide under microwave irradiation at room temperature were tested in this work. The results summarized in Table- 1 that the multi metal oxide catalysts within the studied ranges of percent loading of $\mathrm{Cu}$ and $\mathrm{Co}$ were more active for the hydroxylation of benzene to phenol than the Fe/activated carbon although the increase of the percent loading of second metal decreased the BET surface area and pore volume particularly at high values of metal loading (Table-2).

The effect of different loading amount of second metal oxides supported on activated carbon as catalyst were investigated. Both the different metal loadings of $\mathrm{Cu}$ and $\mathrm{Co}$ in the catalyst were at the same value for all catalysts. The different loading amount of metal oxides obviously influenced the yield of phenol. The increase of the $\mathrm{Cu}$ and $\mathrm{Co}$ loadings improved the benzene conversion. However, the phenol selectivity obviously reduced. The decrease of selectivity at high metal loading could be due to the reduction of dispersion of the catalyst metal. The optimum percent loading of $\mathrm{Cu}$ and $\mathrm{Co}$ which offered the highest phenol yield was 5 wt. $\%\left(\mathrm{Fe}_{5} \mathrm{Cu}_{5} /\right.$ activated carbon) giving a phenol selectivity of more than $75 \%$. The improved yield of phenol by the increase of metal loading was mainly contributed by the increase in the conversion. It is noted that the amounts of metal oxides in the catalysts have the effect on decomposition of $\mathrm{H}_{2} \mathrm{O}_{2}$ to hydroxyl radical and consequently the reactions taking place in the system.

\begin{tabular}{|c|c|c|}
\hline \multicolumn{3}{|c|}{$\begin{array}{c}\text { TABLE-1 } \\
\text { EFFECT OF Cu, Co-Fe/ACTIVATED CARBONCATALYSTS } \\
\text { PREPARED BY IMPREGNATED METHOD ON CATALYTIC } \\
\text { ACTIVITY UNDER MICROWAVE IRRADIATION }\end{array}$} \\
\hline Catalyst & Conversion $(\%)$ & Selectivity (\%) \\
\hline 5 wt. $\% \mathrm{Fe} / \mathrm{C}$ & 28.9 & 100 \\
\hline 2.5 wt. $\% \mathrm{Cu}-5$ wt. $\% \mathrm{Fe} / \mathrm{C}$ & 31.4 & 89 \\
\hline 5 wt. $\% \mathrm{Cu}-5$ wt. $\% \mathrm{Fe} / \mathrm{C}$ & 37.3 & 75 \\
\hline 2.5 wt. $\% \mathrm{Co}-5$ wt. $\% \mathrm{Fe} / \mathrm{C}$ & 29.8 & 78 \\
\hline 5 wt. $\%$ Co-5 wt. \% Fe/C & 32.2 & 71 \\
\hline
\end{tabular}

TABLE-1

\begin{tabular}{lccc}
\multicolumn{5}{c}{ TABLE-2 } \\
\multicolumn{4}{c}{ BET DATA FOR Cu, Co-Fe/ACTIVATED CARBON } \\
CATALYSTS PREPARED BY IMPREGNATED METHOD
\end{tabular}

Effect of the reaction conditions on the yield of phenol under microwave irradiation: Effect of the catalyst amount on the yield of phenol: The results for the effect of the amount of catalyst on the yield of phenol investigated over $\mathrm{Fe}_{5} \mathrm{Cu}_{5} /$ activated carbon at room temperature under microwave irradiation is shown in Table-3. It was found that the catalyst amount increased from 0.2 to $0.3 \mathrm{~g}$, the conversion of benzene increased slowly from 14.8 to $23.4 \%$ and then sharply increased up to $37.7 \%$ when the amount of catalyst was up to $0.4 \mathrm{~g}$, but a further increase in the amount of catalyst inversely caused a decrease in the yield of phenol. The amount of catalyst has the effect on the decomposition of hydrogen peroxide and the amount of hydroxyl radical for this reaction system.

$$
\mathrm{Fe}(\mathrm{II})+\mathrm{H}_{2} \mathrm{O}_{2} \rightarrow \mathrm{Fe}(\mathrm{III})+\mathrm{OH}^{0}+\mathrm{OH}-
$$

The increased amounts of catalyst increased the amount of hydroxyl radical in the reaction which is necessary for the oxidation reaction of benzene to produce cyclohexadienyl (CHD) radical as follows: 


\begin{tabular}{|c|c|c|}
\hline \multicolumn{3}{|c|}{$\begin{array}{c}\text { TABLE-3 } \\
\text { EFFECT OF THE CATALYST AMOUNT ON REACTION } \\
\text { UNDER MICROWAVE IRRADIATION }\end{array}$} \\
\hline Catalyst (g) & Conversion (\%) & Selectivity (\%) \\
\hline 0.2 & 14.8 & 89 \\
\hline 0.3 & 23.4 & 85 \\
\hline 0.4 & 37.7 & 81 \\
\hline 0.5 & 39.7 & 74 \\
\hline \multicolumn{3}{|c|}{$\begin{array}{l}\text { Reaction conditions: } 1 \mathrm{~mL} \text { benzene, } 3 \mathrm{~mL} \mathrm{H}_{2} \mathrm{O}_{2}, 20 \mathrm{~mL} \text { acetonitrile, } \\
35^{\circ} \mathrm{C}, 20 \mathrm{~min}\end{array}$} \\
\hline \multicolumn{3}{|c|}{$\mathrm{OH}^{0}+\| \rightarrow$ Cyclohexadienyl } \\
\hline \multicolumn{3}{|c|}{$\mathrm{Fe}(\mathrm{III})+$ Cyclohexadienyl $\rightarrow \mathrm{Fe}(\mathrm{II})+$} \\
\hline
\end{tabular}

Increasing the amount of catalyst increased the conversion of benzene but decreased phenol selectivity. The phenol was easy to produce byproducts (hydroquinone and benzoquinone), it is therefore essential to control the amount of hydroxyl radical per reactant. Therefore, $0.4 \mathrm{~g} \mathrm{Fe}_{5} \mathrm{Cu}_{5} /$ activated carbon is considered as a suitable amount in this reaction.

Effect of the amount of $\mathrm{H}_{2} \mathrm{O}_{2}$ for the hydroxylation of benzene: The effect of the amount of $\mathrm{H}_{2} \mathrm{O}_{2}$ for the hydroxylation of benzene on the yield of phenol over $\mathrm{Fe}_{5} \mathrm{Cu}_{5} /$ activated carbon at room temperature under microwave irradiation is shown in Table-4. When the amount of $\mathrm{H}_{2} \mathrm{O}_{2}$ increased from 1 to $2 \mathrm{~mL}$, the conversion of benzene increased slowly from 15.8 to $21.4 \%$ and then sharply rose up to $37.7 \%$ when the amount reached to $3 \mathrm{~mL}$. However, when the amount of $\mathrm{H}_{2} \mathrm{O}_{2}$ was further up to $4 \mathrm{~mL}$, the yield of phenol dropped quickly. It can be explained that further oxidation of phenol to hydroquinone or benzoquinone can be occurred with the presence of excessive amount of $\mathrm{H}_{2} \mathrm{O}_{2}$ oxidant. it was difficult to control the selective oxidation to produced phenol. The benzene conversion was increased by the high concentration of oxidant but it decreased the phenol selectivity. So, $3 \mathrm{~mL}$ is chosen as a suitable amount.

\begin{tabular}{ccc} 
TABLE-4 \\
\multicolumn{3}{c}{ EFFECT OF THE $\mathrm{H}_{2} \mathrm{O}_{2}$ AMOUNT ON REACTION } \\
UNDER MICROWAVE IRRADIATION \\
\hline $\mathrm{H}_{2} \mathrm{O}_{2}(\mathrm{~mL})$ & Conversion (\%) & Selectivity $(\%)$ \\
\hline 1 & 15.8 & 88 \\
2 & 21.4 & 84 \\
3 & 37.7 & 81 \\
4 & 39.9 & 72 \\
\hline Reaction conditions: $0.4 \mathrm{~g}$ catalyst, $1 \mathrm{~mL}$ benzene, $20 \mathrm{~mL}$ \\
acetonitrile, $35^{\circ} \mathrm{C}, 20 \mathrm{~min}$
\end{tabular}

Effect of the reaction time on the yield of phenol: The influence of reaction time on the yield of phenol over $\mathrm{Fe}_{5} \mathrm{Cu}_{5} /$ activated carbon at room temperature under microwave irradiation is shown in Table-5. It is obvious that the conversion of benzene increased significantly from 13.8 to $37.7 \%$ when the reaction time increased from 10 to 20 min and after that, the yield decreased sharply with the further increase of reaction time. The sharply decrease of yield may be caused by the further oxidation of the phenol. So, $20 \mathrm{~min}$ is chosen as a suitable reaction time in this reaction.

\begin{tabular}{ccc}
\hline \multicolumn{3}{c}{ TABLE-5 } \\
\multicolumn{3}{c}{ EFFECT OF THE REACTION TIME ON REACTION } \\
UNDER MICROWAVE IRRADIATION \\
\hline Time (min) & Conversion (\%) & Selectivity (\%) \\
\hline 10 & 13.8 & 87 \\
15 & 22.4 & 84 \\
20 & 37.7 & 81 \\
25 & 40.7 & 70 \\
\hline Reaction conditions: 0.4 g catalyst, $1 \mathrm{~mL}$ benzene, $3 \mathrm{~mL} \mathrm{H}_{2} \mathrm{O}_{2}, 20 \mathrm{~mL}$ \\
acetonitrile, $35^{\circ} \mathrm{C}$
\end{tabular}

Effect of the amount of solvent on the yield of phenol: The catalytic performance of the reaction system using different amounts of acetonitrile (e.g., 10, 15, 20, 25, $30 \mathrm{~mL}$ ) over $\mathrm{Fe}_{5} \mathrm{Cu}_{5}$ /activated carbon at room temperature under microwave irradiation is summarized in Table-6. It should be noted that the benzene conversion significantly increased with increasing $\mathrm{CH}_{3} \mathrm{CN}$ amount up to $20 \mathrm{~mL}$ but then decreased with further increase in $\mathrm{CH}_{3} \mathrm{CN}$ amount. Strong interaction between benzene and $\mathrm{OH}^{\bullet}$ formed from $\mathrm{H}_{2} \mathrm{O}_{2}$ is necessary for the formation of phenol. Without $\mathrm{CH}_{3} \mathrm{CN}$, benzene and $\mathrm{H}_{2} \mathrm{O}_{2}$ aqueous solution are clearly divided into two layers. Reaction of benzene with $\mathrm{OH}^{\bullet}$ in the interface cannot proceed effectively. Since $\mathrm{CH}_{3} \mathrm{CN}$ can be dissolved both in benzene and in aqueous solution of $\mathrm{H}_{2} \mathrm{O}_{2}$, adding proper amount of $\mathrm{CH}_{3} \mathrm{CN}$ improves interaction between benzene and $\mathrm{OH}^{\bullet}$ formed from $\mathrm{H}_{2} \mathrm{O}_{2}$ and thereby increases phenol yield, but superfluous addition of $\mathrm{CH}_{3} \mathrm{CN}$ decreases the concentrations of both benzene and $\mathrm{H}_{2} \mathrm{O}_{2}$ and subsequently decreases phenol yield instead. Therefore, $20 \mathrm{~mL}$ is chosen as a suitable solvent amount in this reaction.

\begin{tabular}{ccc}
\multicolumn{3}{c}{ TABLE-6 } \\
EFFECT OF THE SOLVENT AMOUNT ON REACTION \\
UNDER MICROWAVE IRRADIATION \\
\hline Solvent Amount (mL) & Conversion $(\%)$ & Selectivity $(\%)$ \\
\hline 10 & 11.8 & 89 \\
15 & 21.4 & 85 \\
20 & 37.7 & 81 \\
25 & 30.7 & 78 \\
30 & 28.8 & 76 \\
\hline
\end{tabular}

Reaction conditions: $0.4 \mathrm{~g}$ catalyst, $1 \mathrm{~mL}$ benzene, $3 \mathrm{~mL} \mathrm{H}_{2} \mathrm{O}_{2}, 35^{\circ} \mathrm{C}$, $20 \mathrm{~min}$

\section{Conclusion}

The liquid phase hydroxylation of benzene to phenol with hydrogen peroxide catalyzed by Fe/activated carbon with different values of metal loading under microwave irradiation was investigated. $\mathrm{Fe}_{5} \mathrm{Cu}_{5}$ catalyst was found to offer the highest yield. The second metal can improve the phenol production of the typical Fe/activated carbon catalyst. The highest yield of was achieved in the optimum condition under microwave irradiation: $1 \mathrm{~mL}$ benzene, $20 \mathrm{~mL}$ acetonitrile, $0.4 \mathrm{~g}$ catalyst, $3 \mathrm{~mL} 30 \%$ aqueous solution of $\mathrm{H}_{2} \mathrm{O}_{2}, 20$ min reaction time, $35{ }^{\circ} \mathrm{C}$ reaction temperature.

\section{ACKNOWLEDGEMENTS}

The authors are grateful to the Scientific Research Item of Xuzhou Institute of Technology (grant No. XKY2012304) for the financial support. 


\section{REFERENCES}

1. R. Klaewkla, T. Rirksomboon, S. Kulprathipanja, L. Nemeth and P. Rangsunvigit, Catal. Commun., 7, 260 (2006).

2. G.O. Rocha, R.A.W. Johnstone, B.F. Hemming, P.J.C. Pires and J.P. Sankey, J. Mol. Catal. Chem., 186, 127 (2002).

3. F. Xiao, J. Sun, X. Meng, R. Yu, H. Yuan, J. Xu and T. Song, J. Catal., 199, 273 (2001)

4. E. Hensen, Q. Zhu and R. Vansanten, J. Catal., 233, 136 (2005).

5. A.A. Ivanov, V.S. Chernyavsky, M.J. Gross, A.S. Kharitonov, A.K Uriarte and G.I. Panov, Appl. Catal. A., 249, 327 (2003).

6. L.V. Pirutko, V.S. Chernyavsky, A.K. Uriarte and G.I. Panov, Appl. Catal. A Gen., 227, 143 (2002).

7. M. Tatlier and L. Kiwi-Minsker, Catal. Commun., 6, 731 (2005).

8. R. Dimitrova and M. Spassova, Catal. Commun., 8, 693 (2007).

9. Y.Y. Gu, X.H. Zhao, G.R. Zhang, H.M. Ding and Y.K. Shan, Appl. Catal. A, 328, 150 (2007).

10. B. Liptakova, M. Hronec and Z. Cvengrosova, Catal. Today, 61, 143 (2000).
11. H. Liu, Z. Fu, D. Yin, D. Yin and H. Liao, Catal. Commun., 6, 638 (2005).

12. E. Battistel, R. Tassinari, M. Fornaroli and L. Bonoldi, J. Mol. Catal. Chem., 202, 107 (2003).

13. J. Peng, F. Shi, Y. Gu and Y. Deng, Green Chem., 5, 224 (2003).

14. P. Lidström, J. Tierney, B. Wathey and J. Westman, Tetrahedron, 57, 9225 (2001).

15. S.A. Galema, Chem. Soc. Rev., 26, 233 (1997).

16. C. Gabriel, S. Gabriel, E.H. Grant, E.H. Grant, B.S.J. Halstead and D.M.P. Mingos, Chem. Soc. Rev., 27, 213 (1998).

17. B.D.M.P. Mingos and D.R. Baghurst, Chem. Soc. Rev., 20, 1 (1991).

18. P.A. Enquist, P. Nilsson and M. Larhed, Org. Lett., 5, 4875 (2003).

19. C. Bonnet, L. Estel, A. Ledoux, B. Mazari and A. Louis, Chem. Eng. Process., 43, 1435 (2004).

20. D.R. Baghurst and D.M.P. Mingos, J. Chem. Soc. Chem. Commun., 9, 674 (1992). 